\title{
EVIDENCE FOR MEDIATING ROLE OF AFFECTIVE COMMITMENT ON GREEN HUMAN RESOURCE MANAGEMENT AND ORGANISATIONAL CITIZENSHIP BEHAVIOUR
}

\author{
Manita Kusi*, Fuqiang Zhao, and Maroy Prisca Rasoanirina \\ School of Management, Wuhan University of Technology, Wuhan, P. R. China, 430070 \\ *Corresponding author: manyatasth2@gmail.com
}

Published online: 4 June 2021

To cite this article: Kusi, M., Zhao, F., \& Rasoanirina, M. P. (2021). Evidence for mediating role of affective commitment on green human resource management and organisational citizenship behaviour. Asian Academy of Management Journal, 26(1), 113-141. https://doi.org/10.21315/aamj2021.26.1.5

To link to this article: https://doi.org/10.21315/aamj2021.26.1.5

\begin{abstract}
Exploring management fields in terms of green policies is essential to create a footprint on today's global corporate world; it is very important for all staff, employers, stakeholders, and other customers. This work attempts to study the relationship between the management of green human resources and the actions of organisational citizenship with the mediating role of affective commitment. The analysis relied on the emerging theory of abilitymotivation-opportunity (AMO) to use all the green human resource management (GHRM) attributes. Well renowned secondary school of Kathmandu Valley staff participated in the data collection. Three hundred and fifty fully-filled questionnaires were returned through a self-structured sampling tool. Staff having academic qualifications of at least graduate degrees were preferred for better understanding and effective data quality. A widely used PLS-SEM method was applied to analyse small sample-sized studies and ensures the normal distribution of data. The research highlights the GHRM method and its effect on the engagement of workers to their actions in the organisation. In addition, concerning GHRM and organisational citizenship behaviour (OCB), affective commitment (AC) has formed a mediating role. Only secondary schools are included in the study; the outcome is a fruitful review of the effects of GHRM implementation in the education sector. Numerous studies have reconnoitered various variables to link the GHRM with the organisational studies. The complementary partial mediation effect of AC to OCB is an attempt of showing
\end{abstract}

(C) Asian Academy of Management and Penerbit Universiti Sains Malaysia, 2021. This work is licensed under the terms of the Creative Commons Attribution (CC BY) (http://creativecommons. org/licenses/by/4.0/). 
novelty in the field of education sector in the study. The study suggests a globalised study regarding GHRM for future endeavours.

Keywords: green human resource management, organisational citizenship behaviour, affective commitment, PLS-SEM, education sector

\section{INTRODUCTION}

A company considers human capital as one of the key resources of an organisation. Human capital is a bundle of habits, knowledge, and personal attributes including creativity embodied in the ability to act on to produce the economic value (Pasban $\&$ Nojedeh, 2016). This human knowledge is essential for any organisation to accomplish its goal. Turnover, job dissatisfaction, and worker's depressions are some of the lags that may negatively hamper the organisation (Srivastava \& Shree, 2019). Experts are concerned with the trend of the modern world with innovative ideas for better organisational performance to overcome those lags. Countless techniques and ideas influence the organisation's sustainability. In the same path, green human resource management (GHRM) has shown a positive effect on organisational performance as one of the practices observed in most developed countries. Keeping the advancement of human resource management practice in organisations in mind, this study has extensively reviewed the literature about the GHRM practice, its pros and cons, its impact, changes in the behaviour, and effect on organisational citizenship behaviour (OCB) considering some other major variables and their relationship.

Environmental protection is the responsibility of all individuals. Green human resource related studies are trending a lot in these latest years' concerning about global environmental issues. Moreover, previous studies have covered hospitals (Pinzone et al., 2016), hotels (Jackson et al., 2011; Pham et al., 2018; Tariq et al., 2016; Zientara \& Zamojska, 2018), manufacturing firms (Nejati et al., 2017; Yusliza et al., 2017), etc. as research area. However, a research gap in GHRM exists in the context of secondary level education sectors, which is an emerging area of research. GHRM studies have prioritised more on the corporate sector as compared to educational institutes (Anwar et al., 2020). Therefore, this study tried to explore a different study area to show the importance of effort made by all sectors to protect the environment through their field. In arrears to economic and environmental sustainability in developing countries, studies are essential to fill such a literature gap.

Although education sectors produce considerably less pollution compared to other corporate sectors, educational sectors are also equally responsible 
as other organisations for the protection of the environment. Moreover, fastgrowing technologies and the use of IT, stylish equipment have amplified energy consumption. Sustainable use of such resources has urged the education sector to be more concern on the environmental management. A considerable number of educational institutes has come up with green initiatives to mark the responsibility of students as well as employees to preserve the environment. However, the proper and complete implementation of GHRM policies still lacks in those organisations. This would be a plus point to uplift a step from the education sector to environmental protection.

Employees are obliged to respond kindly to common contended issues until they obtain equal financial and emotional benefits from their employer (Antonioli et al., 2013; Blau, 1964). Although OCB is difficult to mandate, the higherlevel staff on any organisation can be encouraged through OCB by shaping an appropriate context. The purpose of this study is to investigate the interrelation between GHRM and OCB through the mediating effect of the commitment of the employees involved in the study. The objectives of the study are: (1) to investigate the relationship of GHRM with OCB, and (2) to assess the role of the affective commitment (AC) of employees between GHRM and OCB.

Our findings give the following contributions. First, based on the ability-motivationopportunity (AMO) framework, the finding clarifies an important contribution to the mediating role of AC towards the effect of green practices on OCB. Second, the finding provides an empirical study that gives a better understanding of the necessity of these green practices applications to boost employee's voluntary eco-behaviour in the education sector. Originally, this study tried to explore the positive association of all three AMO-based green human attributes to the OCB in contrast to the previous study that found only one latent variable significance relation conducted (Pinzone et al., 2016).

\section{THEORETICAL PERSPECTIVE AND HYPOTHESES}

This section of the study will explore GHRM and its impacts. Further, the hypotheses will be presented on the direct relationship with GHRM and OCB. Secondly, it will make a review of the mediation relation between GHRM, AC, and OCB. 


\section{The Direct Effect of GHRM on OCB}

Pinzone et al. (2016) defined OCB as "individual behavior that is discretionary, not directly or explicitly recognized by the formal reward system and in the aggregate promotes the efficient and effective functioning of the organization and is the standard mode of behavior" (p. 2). According to one of the researchers, GHRM is positively influenced by workplace behaviour (Dumont et al., 2017). The upperlevel staff can encourage the emergence of collective behaviors by approaching support through appropriate intervention, for instance, GHRM (DuBois \& Dubois, 2012; Harvey et al., 2013; Paillé et al., 2014; Zibarras \& Coan, 2015).

The mediating role can be explained by using social exchange theory. The social exchange theory provides an explanatory framework about the perception of the employee connected with the behaviour they admire. The theory focuses on the norms of reciprocity within the social relationship (Alfes et al., 2013). Employees would reciprocate the positive treatment they received from the organisation by developing an emotional attachment to this employer because they feel the obligation to care about the organisational welfare and to help the organisation reach its goals. This influences the commitment of the employees in the organisation. Individuals pursue an equal trade arrangement with their company according to this principle. If employees perceive a high risk, there will be a disparity in the exchange relationship and these employees will be frustrated and mistrustful. In consequence, their commitment to the organisation and desire to remain would diminish (Liu \& Deng, 2011).

It is argued that employees are obliged to respond kindly once they receive equivalent financial and emotional benefits from their organisation (Antonioli et al., 2013; Blau, 1964). Although OCB is difficult to mandate, the higher-level staff on the organisation can be encouraged through OCB by shaping an appropriate context such as GHRM (DuBois \& Dubois, 2012; Harvey et al., 2013; Opatha, 2013; Paillé et al., 2014). Organ (1990) defined OCB as an appropriate eco-friendly approach. OCB is "employee behavior that is above and beyond the call of duty and is therefore discretionary and rewarded in the context of an organization's formal reward system" (Organ 1990, p. 46).

\section{AMO Theory}

Although AMO theory is the most comprehensive in understanding GHRM contribution towards the organisational environmental performances, very fewer studies have applied the complete AMO framework in research models. The environmental performance through OCB with the linkage mechanism of GHRM 
practices is often neglected (Anwar et al., 2020). AMO model is a tremendous and organised framework with an empathetic relationship between human resource management and performance (García \& Tomas, 2016). AMO theory describes that high-performance work (HPW) practices is a set of distinct but are interrelated to human resource practices that are combined based on three aspects. AMO theory suggests that three employee-related components of the work system contour employee's characteristics and contributes goal achievement. Organisational needs are protected by a system that takes care of the knowledge, encouragement, and resources of the employee (Almutawa et al., 2016; Moktadir et al., 2018). Some authors point out that a managerial perspective can explain the adoption of an employee-based perspective better than by the AMO model (Bos-Nehles et al., 2013; García \& Tomas, 2016). This view suggests that human resource packages are well-designed of practices that focus on-line manager's aptitudes to implement human resource practices (A), their motivation to enable them (M), and the organisational support to commence necessary changes $(\mathrm{O})$ (Bainbridge, 2015; Owino \& Kwasira, 2016).

The study presents GHRM ensuing the deep-rooted AMO theory as recommended by prior researchers (Renwick et al., 2013). AMO hypothesis contends that human resource management practices contribute to organisational execution by expanding the degree to which employees can (i.e., have the competencies), need (i.e., have the inspiration), and can (i.e., have openings) lock-in in behaviours that advantage the association such as OCBs. According to this view, GHRM practices are:

1. Competence building practice including the training and received talent they have that will affect the ability of the employee knowledge (Yusliza et al., 2017),

2. Performance management practice covering the motivating factors and appraisal of the organisation level towards the employee (Tang et al., 2018), and

3. Employee involvement practices which will provide employment opportunity through ad-hoc involvement (Tariq et al., 2016).

\section{Green competence building practices (GCB)}

GCB is the cornerstone to enhance existing knowledge of an individual (Jafri, 2012). GCB practices include green recruitment and selection, green training, and development initiatives to strengthen the employee's environmental knowledge (Yusliza et al., 2017). The employee's strength on environmental knowledge leads 
to the worker's recognition of environmental issues and immediate appropriate action to minimise the negative impacts at the workplace (Anwar et al., 2020). Kim et al. (2019) hypothesised the positively significant relation of GHRM on the employee's eco-friendly behaviour. Moreover, communicating organisations green interest during recruiting and taking into account the environmental values of individuals in the employee selection phase likely to improve employee knowledge and understanding (Renwick et al., 2013). The selection of the perfect employee is a challenge for organisations and uplifting them after recruitment is major even to make them more committed to giving their best (Deshwal, 2015; Jackson et al., 2011; Siyambalapitiya et al., 2018). Ability-enhancing practices are primarily related to training and career (Kim et al., 2019; Quansah, 2013). It is possible that involving workers in implementing green policies and delivering green training would increase employees' awareness, expertise, and make them more mentally willing to participate in green behaviours (Chaudhary, 2020). Based on the arguments, we hypothesised the following:

H1a: GCB practices are positively associated with OCB.

\section{Green performance management practices (GPM)}

The second variable for the AMO theory is the motivation (Knies \& Leisink, 2014) which can be considered by using human resource practices applied for the employee motivating factors, for instance rewards and performance appraisal. Norton et al. (2015) explained the motivation theory as the factors that drive the decision to engage in a particular behaviour as well as the intensity and persistence of effort demonstration. Performance management usually motivates them to achieve the organisational goal (Haddock-Millar et al., 2016). Human resource department can play a remarkable approach on human resource policies with recurrent appraisal of workers' capability inciting employers' motivational aspect (Bainbridge, 2015). Reward practices essentially include as a motivational part in fortifying desired practices as the line is improbable to organise individual's administration within the non-attendance of motivation (Kaur, 2013; Rajiani et al., 2016). Therefore, we hypothesised:

H1b: GPM is positively associated with OCB.

\section{Green employee involvement practices (GEI)}

GEI practices refer to the employee with the opportunity to have their initiative towards organisational progress (Arulrajah \& Opatha, 2016; Arulrajah et al., 2015). Job descriptions that specify the responsibilities of human management 
provide a better chance to contribute in decision making regarding the issues (Juma \& Lee, 2012). The more workers involved in environmental conservation programmes, the more will be their devotion to environmental obligations. Employees can write by newsletter participation, and build green teams and committees that solved problems. It will boost and help them learn the efficiency of environmental organisation activities (Srivastava \& Shree, 2019). Further, with growing knowledge of environmental management practices and cultivating a culture of environmental conservation also enables the value enhancement and problem-solving capabilities on environmental issues (Anwar et al., 2020). Thus, based on the literature, this study hypothesised:

H1c: GEI practices are positively associated with OCB.

\section{The Direct Relation of Affective Commitment to OCB}

Commitment refers to the psychological state that identifies and describes the distinctive characteristics of employee relations with the organisation as well as the result of the decision to continue or discontinue membership with an organisation. Whereas one of the aspects of commitment that refers to the attachment to the organisation represents AC (Meyer et al., 1993). According to Meyer et al. (1989), organisational commitment encompasses of three dimensions: affective commitment, normative commitment, and continuance commitment. The AC is closely linked to the optimistic feelings associated with the workplace and a sense of attachment that helps them to meet their needs and happiness. AC is a positive feeling towards the organisation. Continuance commitment is associated with cost calculation linking to organisation dropout. Besides, normative commitment is associated with the sense of more obligation to stay within the organisation (Meyer et al., 1993). Research shows that workers with highly defined AC are ideally suited to an organisation then lower level. Similar but weaker effects can be observed when normative commitment is manifested. In the case of continuance commitment, the worst results were accumulated (Grego-Planer, 2019).

Podsakoff and Organ (1986) describe OCB as behaviours that do not appear in the formal job description but promote task success within the organisation. Such behaviours include helping new employees catch up, job fatigue hours at work, extra duties, etc. Psychological contract and professional engagement also had an encouraging effect on OCB-related service (Shaaban, 2018). One of the researchers found that an employee's engagement in OCBs may increase the exchange of knowledge and organisational performance (Lin \& Peng, 2010). An empirical proof confirmed that workers with a highly defined AC are ideally suited to organisations other than lower-level organisations (Grego-Planer, 2019). AC 
strongly impacts the organisational outcome and the theory suggests a positive correlation between AC and OCB (Carmeli \& Colakoglu, 2005). Based on the literature, this study posed the following hypothesis:

H1d: AC is positively associated with OCB.

\section{The Mediating Role of Affective Commitment}

Research based on AC had been a cornerstone in elevating the human capital of organisations. The ability, motivation, and opportunity mode present a specific way of explaining human resource practices that link with the behaviour among the employees. This lead to motivate the employees to feel highly committed towards the organisation, their colleagues, and their duties and are willing to go an extra mile. Organ (1990) put forward a social exchange theory where he conceptualised $\mathrm{AC}$ as a sense of psychological connection and is a precedent of OCB. According to social exchange theory, work activities can be explained but a process in which an individual feels some form of responsibility to reciprocate the benefits of an organisation. Hence, AC to an organisation involves frequently and repeated positive experiences between the employee and their firms.

Social identity theorists suggest that a close association with an organisation is likely to display high citizenship behaviour (Eisenberger et al., 2014). Social identity theorists have emphasised the cognitive component of identification. Cognitive identification is strongly related to $\mathrm{AC}$ which in turn result in various citizenship behaviour (Carmeli \& Colakoglu, 2005). They argued that AC is the highest degree of attachment to his/her organisation that can be formed and this connection will motivate him/her to support the organisation he/she is associated with. According to Carmeli and Colakoglu (2005), traditional concept of AC and continuance commitment were better predictors of employee behaviour (i.e., organisational citizenship and impression management). Meyer et al. (1989) mentioned among continuance commitment, normative commitment, and $\mathrm{AC}$, the $\mathrm{AC}$ had the strongest and most beneficial relationship to absenteeism, job performance, OCB (e.g., taking on roles beyond job description), stress, and work-family conflict. Specifically, those most affectively committed indicated to have low absentee rates, high levels of job performance, elevated levels of OCB, and low levels of stress and work-family conflict. The result explores AC had a positive association while continuance commitment had a negative association (Shore \& Wayne, 1993).

Moreover, the reviewed research by Mercurio (2015) showed that AC is more predictive of significant organisational outcomes such as turnover, absenteeism, 
and habits of organisational citizenship than the organisational committers' conceptual behavioural or transactional constructs (Busari et al., 2017; Meyer et al., 2002). Some authors pointed out that the use of a contingent perspective can comprehend to handle the mentioned issue by integrating mediating variables. Examples of mediating variables are employee's characteristics, for example attitudes and behaviour (Bos-Nehles et al., 2013; Fitzgerald et al., 2011), linemanagers features such as leadership style or AC (Stinglhamber et al., 2015), or organisational level dimensions such as climate or culture cited in empirical research (Caesens et al., 2016).

Empirical evidence suggests that $\mathrm{AC}$ is positively associated with other desirable outcomes (e.g., intention to stay, employee presence, $\mathrm{OCB}$, employee health, employee well-being), while in some cases the other two commitment components reveal negative associations with outcome measures (Meyer et al., 2002). Benn et al. (2015) explained the relationship between AC and OCB among employees in small and medium companies (Bombiak \& Marciniuk-Kluska, 2018; Davies \& Crane, 2010) with limited resources. This study mostly focused on AC with reference to prior study (Elorza et al., 2011; Shen et al., 2016). Research on Dutch health care organisation was conducted which showed AC and OCB are relevant outcome indicators for the organisation (Boselie, 2010). Based on that literature, we postulated the following hypotheses:

H2a: AC mediates positive relation between GEB and OCB.

$\mathrm{H} 2 \mathrm{~b}$ : AC mediates positive relation between GPM and OCB.

H2c: AC mediates positive relation between GEI and OCB.

A prior research empirically verified the mediating role of $\mathrm{AC}$ on green human resource practices and citizenship behaviour. Pinzone et al. (2016) concluded that only GEI showed a significant effect on the mediation relation between $\mathrm{AC}$ and OCB while AC did not mediate the relation of GPM and GCB to OCB. This study attempted to elaborate on their relationship in the context of the education sector. 


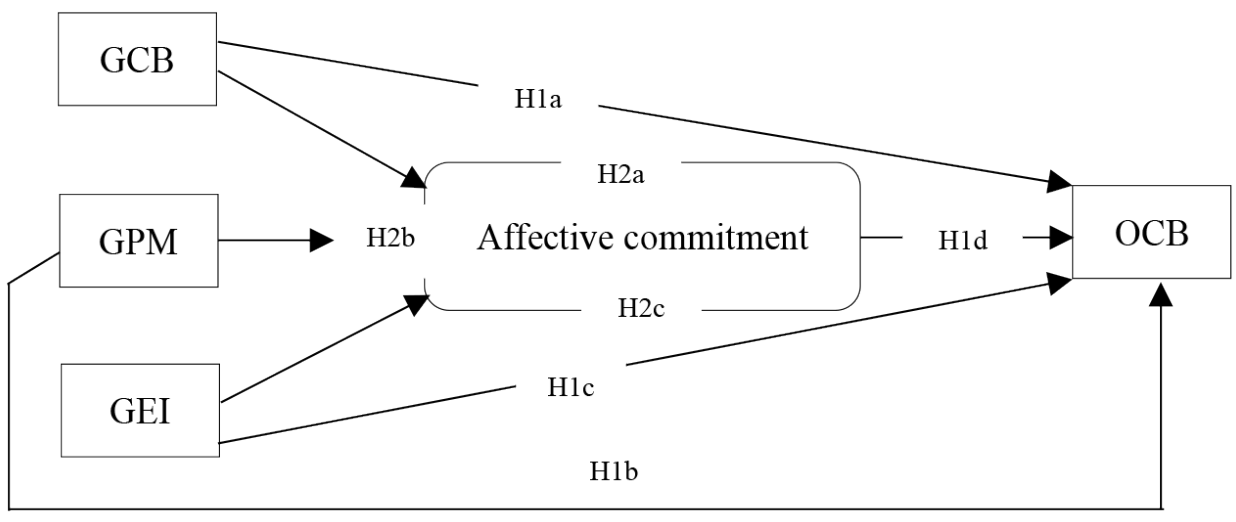

Figure 1. Conceptual framework

\section{METHODOLOGY}

The study considered the secondary schools of Kathmandu Valley as its research object. Being the capital of country Nepal, most of the education sectors with well-qualified teaching staffs commonly centralise within the valley. Selection of qualified respondents will upgrade the output of study as the data quality is highly proportional to the qualification of the respondents to response. The questionnaire consisted of items representing respondents' attitudes and opinions towards the green innovation practices, the related factors in addition to the aggressive gain, the organisational, and the environmental overall performance. The target population of the study consists of employees and managers, both middle and senior level, working in organisations that had adopted green innovation practices. A convenience sampling approach made the data collection easier and faster. To evaluate the model and examine the hypotheses, the latent reflective measures extracted from several research discoveries and some mandatory modifications were made to the items to make them suitable for the study framework. The questionnaire was testified from 10 senior academics schools in Nepal (Kathmandu Valley) to gauge its validity. Further, the researchers modified the data collection tool accordingly. Based on their feedback, a few items were altered or reworded. It made them more suitable for the concerned study site. The researchers then collected the required data applying a self-administered questionnaire circulated to the academic teachers at both private and public schools in Nepal where the medium of teaching instruction is English.

Respondents were selected mainly from three main districts of Nepal (Kathmandu, Bhaktapur, and Lalitpur). The population of homogeneous group contributes to 
forecasting results theoretically in exact way in compared to that of heterogeneous group. Keeping that on mind, the study included homogeneous group of sample population (Muehling, 1987). Moreover, the present study abandoned localisation with translation of questionnaires into mother language as the respondents were familiar with English language.

The selection of the participants was available from the local education authorities. Data collection were gathered through personal e-mails and direct face-to-face contacts. Further, we invited the school to participate in the research and arranged a visit to their premises to collect data, if they agreed.

To measure the model and examine the hypotheses, we extracted reflective latent dealings from several research discoveries and made some obligatory amendments to the items to make them suitable for the study framework. The questionnaire contained five constructs with 18 items (see Appendix). According to the number of the latent variable, each variable consists of 10 responses, this study exceeds minimum requirement of the sample size (Wolf et al., 2013). Out of the 400 survey tools distributed, only 350 filled questionnaires were received. In terms of demographic profiles of the respondents, $72.2 \%$ participants were male employees and $28 \%$ were female; more than half of the respondents (55.6\%) were postgraduates and were above 30 years of age; $56.7 \%$ of the sample population were involved in government schools whereas $31 \%$ of the sample population enrolled in the job for more than 10 years. The questionnaire was designed using a universal English language with a 5-point Likert scale anchored at " 1 = strongly agree" to " $5=$ strongly disagree." The preference of the 5-point Likert scale over the 7-point is that the 5-point scale appears to be less confusing and to increase response rate and reliable data (Revilla et al., 2014).

\section{RESULTS}

This study used SMART PLS 3.2.1 and SPSS 23 software for data analysis. This analysis is applicable in the small sample sized study and ensures the normal distribution of data. Firstly, the study conducted a preliminary analysis to check the accuracy of data to use in PLS model analysis. Secondly, the validity of the measurement model conceded out followed by the validity of the structural model, with the analysis of hypotheses tests. 


\section{Preliminary Analysis}

Data screening concluded with substitution of missing values with the mean of the corresponding non-missing values. Every research might face the issue of common method bias, and this study is not away from this bias. To detect the possible common method bias, we used Harmon's one-factor test in SPSS to check for common method bias from our data set. The result revealed a 30.894\% variance, which is less than the threshold of 50\% (Podsakoff \& Organ, 1986).

\section{Analysis and Validity of Measurement Model}

This section presents findings associated with the study of the reliability and validity of the constructs. After performing the loading of the relevant test, the outputs exhibit satisfactory values greater than 0.7 to their respective constructs as shown in Table 1. Moreover, Cronbach's alpha and composite reliability (CR) of all the constructs also exceed the value 0.7 which meets the verified internal consistency reliability (Tenenhaus et al., 2005). Besides, the FornellLarcker criterion and cross-loadings consideration are the dominant approaches for evaluating discriminant validity. Considering the same approach, Table 2 explores the evaluation of the discriminant validity of all the study constructs with their cross-loadings. Furthermore, all the constructs exhibit an average variance extracted (AVE) value over the cutoff level of 0.5 for their convergent validity. Besides, the heterotrait-monotrait (HTMT) ratio of all constructs was below 0.85 level as demonstrated in Table 3. Hence, these results strongly explore the evidence of the discriminant validity of the measurement model's construct.

Table 1 presents indicator items' loading, Cronbach's alpha, CR, and AVE values showing the assessment of measurement quality of the model's constructs. Values loading greater than 0.5 shows the indicator reliability. The internal consistency is measured by Cronbach's alpha and CR values greater than 0.7 (Hair et al., 2012). The AVE value above 0.5 represents the convergent validity (Memon \& Rahman, 2014).

This study employed average validity using two methods - comparing the root square mean values of AVEs with the corresponding coefficients and examining HTMT. The values of AVEs for all the variables are illustrated in Table 1. This means that the latent variable of this study had a high convergent validity since all the mentioned variables exceed 0.50 value as recommended (Fornell \& Larcker, 1981). Using the HTMT as a criterion involves comparing it to a predefined threshold. If the value of the HTMT is higher than this threshold, one can conclude that there is a lack of discriminant validity (Henseler et al., 2015). 
Table 1

Assessment of measurement quality of model constructs

\begin{tabular}{llcccc}
\hline Construct & Indicator & Item loading & Cronbach's alpha & CR & AVE \\
\hline Affective commitment & AC1 & 0.886 & 0.886 & 0.929 & 0.814 \\
(AC) & AC2 & 0.892 & & & \\
& AC3 & 0.928 & & 0.937 & 0.787 \\
Organisational & OCB1 & 0.862 & 0.91 & & \\
citizenship behaviour & OCB2 & 0.875 & & & \\
(OCB) & OCB3 & 0.916 & & 0.943 & 0.806 \\
& OCB4 & 0.894 & & & \\
Green performance & GPM1 & 0.903 & 0.92 & & \\
management (GPM) & GPM2 & 0.92 & & & \\
& GPM 3 & 0.894 & & & \\
& GPM 4 & 0.872 & & & \\
Green employee & GEI2 & 0.899 & 0.896 & & \\
involvement (GEI) & GEI3 & 0.887 & & & \\
& GEI4 & 0.937 & & & \\
Green competence & GCB1 & 0.913 & 0.907 & & \\
building (GCB) & GCB2 & 0.803 & & & \\
& GCB3 & 0.908 & & & \\
& GCB4 & 0.898 & & & \\
\hline
\end{tabular}

Table 2 demonstrates the square root of the AVE value for each construct and its correlations with other constructs. Diagonal bold values in the table represent the square root of AVE whereas non-diagonal elements represent correlations of a construct with their constructs. The discriminant validity is met when the square root of AVE of a construct is greater than its correlation coefficients with other constructs (Hair et al., 2012). 
Table 2

Fornell-Larcker criterion analysis

\begin{tabular}{lccccc}
\hline & AC & OCB & GPM & GEI & GCB \\
\hline AC & 0.902 & & & & \\
OCB & 0.609 & $\mathbf{0 . 8 8 7}$ & & & \\
GPM & 0.272 & 0.464 & $\mathbf{0 . 8 9 8}$ & & \\
GEI & 0.277 & 0.411 & 0.205 & $\mathbf{0 . 9 0 8}$ & \\
GCB & 0.269 & 0.523 & 0.259 & 0.363 & $\mathbf{0 . 8 8 2}$ \\
\hline
\end{tabular}

Table 3

HTMT criterion to assess discriminant validity

\begin{tabular}{llllll}
\hline & AC & OCB & GPM & GEI & GCB \\
\hline AC & & & & & \\
OCB & 0.674 & & & & \\
GPM & 0.291 & 0.502 & & & \\
GEI & 0.304 & 0.504 & 0.214 & & \\
GCB & 0.276 & 0.553 & 0.266 & 0.231 & \\
\hline
\end{tabular}

Note: The HTMT ratio values of the given table expose the correlations between the model's constructs where the HTMT value of less than 0.85 indicates discriminant validity

\section{Analysis and Validity of Structural Model}

In this section, we calculate the coefficient of determination $\left(\mathrm{R}^{2}\right)$, effective size $\left(\mathrm{f}^{2}\right)$, predictive relevant value $\left(\mathrm{q}^{2}\right)$, multi-collinearity (VIF), and check the validity of all parameters as structural model validity test.

Henseler et al. (2015) considered coefficient of determinant results that exceed the cutoffs $0.67,0.33$, and 0.19 as "substantial," "moderate," and "weak," respectively. The $\mathrm{R}^{2}$ value for affective commitment (AC) is 0.178 , which is weak while the outcome variable showed moderate with value OCB 0.37 as per the cutoff range. Besides, previous research has mentioned that in a well-fitting model, the structural variance inflation factor (VIF) coefficients should not exceed 4.0 (some use the more lenient criterion of 5.0) (Barclay et al., 1995). In our case, all VIFs of the indicators were below the criteria indicating sufficient construct validity for our formative indicators, or in another word, there is the absence of collinearity within the predictive construct. 
Table 4

Results of multi-collinearity assessment

\begin{tabular}{lcc}
\hline Predictor construct & Dependent variable & VIF \\
\hline GPM & AC & 1.101 \\
GEI & AC & 1.207 \\
GCB & AC & 1.226 \\
\hline
\end{tabular}

Table 5 illustrates the direct association of the GHRM attributes, AC to OCB. GCB showed the significant positive association with OCB $(\beta=0.12, p<0.05)$. The result matches the significant output with prior study (Chaudhary, 2020; Yusliza et al., 2017) supporting the first hypothesis H1a. Similarly, GPM ( $\beta=0.193$, $p<0.05)$ showed positive association with OCB supporting H1b. The result was consistent with the results of the literature provided (Norton et al., 2015; Yusliza et al., 2017), and GEI $(\beta=0.105, p<0.05)$ was positively related to OCB. The result was significant as that of the previous studies supporting hypothesis H1c (Chaudhary, 2020; Yusliza et al., 2017).

Further, to generate standard error and $t$-values, this study also used the re-sampling bootstrap method with 5,000 samples along with each bootstrap sample for the same number of observations. Table 5 summarises the result for an assessment of the estimated path relationship among the latent variables in the models. The $\mathrm{f}^{2}$ effect size measure is another name for the $\mathrm{R}^{2}$ change effect. The $\mathrm{f}^{2}$ coefficient is given by ( $\mathrm{R}^{2}$ original- $\mathrm{R}^{2}$ omitted $) /\left(1-\mathrm{R}^{2}\right.$ original $)$. The $\mathrm{f}^{2}$ equation expresses how large a proportion of unexplained variance is measured by $\mathrm{R}^{2}$ change (Hair et al., 2012). Following another researcher, 0.02 represents a "small" $\mathrm{f}^{2}$ effect size, 0.15 implies a "medium" effect, and 0.35 signifies a "high" effect size (Shanmugapriya $\&$ Subramanian, 2016). Further, a clear illustration of the values of $f^{2}$ for each variable is shown in Table 5. Finally, the analysis also considered the blindfolding procedure. Blindfolding is used to calculate the cross-validated measures of model predictive accuracy $\left(\mathrm{Q}^{2}\right)$. $\mathrm{Q}^{2}$ values larger than zero for a specific reflective endogenous latent variable indicate the path model's predictive relevance for a particular construct, and $\mathrm{Q}^{2}$ values of zero or below indicate a lack of predictive relevance (Shanmugapriya \& Subramanian, 2016). The outer model connecting latent constructs to their indicators shows that the outer model has a high degree of $\mathrm{Q}^{2}$ about the endogenous factor. From the above output of $\mathrm{R}^{2}, \mathrm{f}^{2}, \mathrm{Q}^{2}$, and VIF prove that our model is also structurally valid. 
Table 5

Results of hypothesis testing

\begin{tabular}{llllllll}
\hline Hypothesis & Relation & $\boldsymbol{\beta}$-value & Std. error & $\boldsymbol{t}$-value & $\boldsymbol{p}$-value & $\mathbf{f}^{2}$ & $\mathbf{Q}^{\mathbf{2}}$ \\
\hline H1a & GCB $\rightarrow$ OCB & 0.120 & 0.065 & 1.763 & $0.0078^{* *}$ & 0.152 & 0.009 \\
H1b & GPM $\rightarrow$ OCB & 0.105 & 0.051 & 1.959 & $0.0051^{* *}$ & 0.342 & 0.024 \\
H1c & GEI $\rightarrow$ OCB & 0.193 & 0.086 & 2.252 & $0.025^{*}$ & 0.221 & 0.015 \\
H1d & AC $\rightarrow$ OCB & 0.196 & 0.058 & 3.315 & $0.001^{* *}$ & 0.588 & 0.272 \\
\hline
\end{tabular}

Notes: Significance at $1 \%$ and $5 \%$ levels are denoted by ${ }^{* *}$ and ${ }^{*}$, respectively. The $\mathrm{f}^{2}$ denotes the effect size of the path's exogenous variable on its endogenous variable. As a rule of thumb, $\mathrm{f}^{2}$ values of $0.02,0.15$, and 0.35 represent the cut-off values for small, medium, and large effects (Henseler et al., 2015).

\section{Mediating Effect}

To test the mediation hypothesis, the bootstrapping process calculated the indirect effect. If the confidence interval does not straddle zero, it concludes that mediation exists. The $95 \%$ confidence interval bootstrap estimate for the indirect effect of the examined variable (Hair et al., 2012). AC mediates the relation of GCB, GPM, GEI, and OCB. This study found that AC to OCB mediates all three GHRM attributes significantly different from zero at $p$-value [where ** denotes $1 \%$ level of significance, $*$ denotes $5 \%$ level of significance $(p<0.001 * *$ and $\left.0.05^{*}\right)$ ] as illustrated in Table 6 , providing support for hypotheses 2 . The mediating role of $\mathrm{AC}$ to GEI found to be significantly different at $p$-value less than $0.01[\mathrm{GEI} \rightarrow \mathrm{AC} \rightarrow \mathrm{OCB}(\beta=0.09 ; p<0.01)]$ which matches the significant result of prior researchers, Pinzone et al. (2016) which support H2c. In contrast, the relationship between GPM [GPM $\rightarrow$ AC $\rightarrow$ OCB $(\beta=0.107$; $p<0.01)]$ and GCB practices [GCB $>\mathrm{AC}>\mathrm{OCB}(\beta=0.078 ; p<0.05)]$ with $\mathrm{AC}$ to OCB were also found to be significant in this study. The result supported our hypotheses $\mathrm{H} 2 \mathrm{a}$ and $\mathrm{H} 2 \mathrm{~b}$ adding empirical evidence for the positive significant relation. Prior research done by Pinzone et al. (2016) found insignificant mediating effect of AC on the relation of GPM and GCB to OCB. This study added new evidence of positive significant mediating effect of AC on GCB, GPM to OCB relation. The results of the mediation test show the partial mediation effect (Baron \& Kenny, 1986) of AC on the relationship between GHRM and OCB, supporting all mediating hypotheses 2 .

Here, all the mediation is complementary partial mediation as all direct relations in Table 5 and an indirect relations in Table 6 are in the same orientation (positive direction) (Baron \& Kenny, 1986). For instance, in Table 5, GPM $>$ OCB have positive beta value of 0.105 and in Table $6, \mathrm{GPM} \rightarrow \mathrm{AC} \rightarrow$ OCB have beta value of 0.107. All other variables showing mediating effect flows with the same direction. 
Therefore, there exist complementary partial mediation. Moreover, AC mediates GPM $>$ OCB relation in most with the highest $t$-value of 2.85 .

Our result excitingly supports the expectation that GCB, GPM, and GEI positively contribute to AC and thus to OCB. A novel empirical evidence is presented in this study with positive significance of all three attributes of GHRM. This study filled the gap from a previous hospital-based research (Pinzone et al., 2016) that concluded the significance effect of only a single attribute of GHRM generated from the AMO model, i.e., the positive significance of GEI to AC to OCB. From this, it can be concluded that employees actively participate in greening the organisation when the company ask them to do so and provide frequent communication regarding the pros of environmental improvement. Moreover, education sectors have embraced the available knowledge and skill of the employees and have used it to improve the organisation's quality in its sustainable activities. Educational institutes are providing proper motivational aspects by effective performance management.

Table 6

Test on indirect effect relation

\begin{tabular}{lllllll}
\hline Relation & $\begin{array}{l}\text { Std. } \\
\text { beta }\end{array}$ & Std. error & $\boldsymbol{t}$-value & $\boldsymbol{p}$-value & $\begin{array}{l}\mathbf{5 \%} \text { CI } \\
\mathbf{L L}\end{array}$ & $\begin{array}{l}\mathbf{9 5 \%} \text { CI } \\
\mathbf{U L}\end{array}$ \\
\hline $\mathrm{GCB} \rightarrow \mathrm{AC} \rightarrow \mathrm{OCB}$ & 0.078 & 0.037 & 2.035 & $0.021^{*}$ & 0.02 & 0.139 \\
$\mathrm{GEI} \rightarrow \mathrm{AC} \rightarrow \mathrm{OCB}$ & 0.090 & 0.033 & 2.718 & $0.003^{* *}$ & 0.04 & 0.147 \\
$\mathrm{GPM} \rightarrow \mathrm{AC} \rightarrow \mathrm{OCB}$ & 0.107 & 0.037 & 2.85 & $0.002^{* *}$ & 0.047 & 0.169 \\
\hline
\end{tabular}

Note: $t$-value $\geq 1.96$ at $p=0.05^{*}$ significance level; $t$-value $\geq 2.58$ at $p=0.001^{* *}$ significance level

\section{DISCUSSION}

The first hypothesis sought to find a significant positive relationship between GHRM and OCB. Employee's ability, performance management, and involvement in organisational activities induce to exercise a higher level of OCB. Therefore, human resource practices adopted by secondary level schools lead to a higher level of citizenship behaviour. The study supported all direct relationships, i.e., green human resource practices in any organisation will lead to better OCB (Anwar et al., 2020). The result extends the findings from previous studies, which identified the green human resource practice in collective citizenship behaviour in the medical human resource staff (Pinzone et al., 2016). From the analysed result, Table 5 illustrates the direct association of the GHRM attributes, AC to OCB. 
In addition, one of the prior studies revealed that intervening variable highly influences the relation between GHRM and OCB than direct relation. For instance, Luu (2019) implemented the role of collecting green crafting as a mediator and environmentally specific servant leadership as a moderator. The finding from the study demonstrated those positive ties between GHRM and individual as well as collective OCB as a mediator by collective green crafts. Environmental relevant leadership of servant also has been found to improve the positive relation between GHRM and collective green crafting as well as OCB. Hence, the study reference gave strong support for our findings to add empirical evidence on the positive association of the intervening variables to improve the relation of GHRM and OCB (Luu, 2019).

The second hypothesis endeavoured to find a mediation relationship between AC and OCB. Our result provides support for the hypothesis. Testing this hypothesis revealed novelty in an indirect significant path between GHRM and OCB, and a direct significant path between GHRM and OCB. This means that AC partially mediates the relationship between GHRM and OCB. They indicate that AC can improve the OCB of the employees, ensuring the more effective approach of performance management, employee involvement, and considering their ability (Norris \& Levy, 2004). Although most of the prior study deals with the implementation of GHRM in an organisation, there is a research gap in the study of GHRM in the higher-level education sector sense, particularly in Nepal. Moreover, this study shed the light on the intervening role of $\mathrm{AC}$ with the positive significant relation of all GHRM attributes based on the AMO theory to OCB.

Contrary to the relation explored by the previous study of similar output in a health-based study (Pinzone et al., 2016), the above result supports that green competence building positively contributes the AC and thus OCB. According to the findings, this study concludes that the secondary level schools have enhanced the employee's knowledge and skills as well as motivated the employees towards greening the organisation. Regarding employee's involvement, the positive significant result confirms that when employees had to participate in the design and implementation of green activities, they provided frequent communications about the benefits that changes would produce and allow making suggestions and improvements on environmental matters. These lead to the internalisation of green changes and improves AC.

Similarly, the performance management of the employees equally brings a positive impact on the commitment of the employees towards the organisation. Some of the past research has raised concerns regarding the effectiveness of performance management in the healthcare sector, education sectors, manufacturing companies, 
and sports companies (Haddock-Millar et al., 2016). Promotions and rewards which recognise and appreciate green performance encourage employees to engage in green activities and contribute to them (Renwick et al., 2013). However, this study showed a positive effect of performance management on an employee's commitment and thus leading better OCB. Overall, this research contributes to the accumulation of empirical evidence on the relation between the GHRM and OCB with the intervening effect of AC.

Our study also has significant implications for practice. To the best of our knowledge, this is the first study conducted on GHRM in the educational sector in the Asian context. The mediating relation explored in this study added significant results in all three GHRM attributes, which were not fully significant in other studies done previously with similar attributes and output as mentioned earlier in the results section. Hence, the study has added novelty that might be helpful for the future researchers those are interested in this kind of study.

First, this study provides managers with an evidence-based indication of the essence of GHRM practice in the organisation. This allows them to prioritise their intervention. Besides, managers will allow the active involvement of the employees as well as motivate them in green activities to contribute to a green sustainable organisation. Secondly, prioritisation of the competence building among the employees can improve the sustainable organisation image. The education sector composes all the future generations who must be clear about the global change and solution to make to global protection in every field. The output from the study can truly affect this aspect. The feasible use of this research is to focus on and reinforce the major human management system of the education sector. Thirdly, the significant mediating effect of all three variables is one of the interesting aspects of this research. This marked a bridge to fulfill the research gap. Future research in this study in various other areas will mark significance in the global scenario.

\section{CONCLUSION}

The findings of this study make a remarkable contribution to fulfill the literature gap. First, the results explore the relationship between AC and OCB. This study has identified the employee's perception of GHRM as an effective determinant to change the OCB. The findings are reliable with the result of Paillé et al. (2014) confirming that the nature of psychological relations with the organisation and employees to manage the environment of the working company rely on the OCB and environmental affairs. Further, this study also invokes the relation of employee's organisational commitment with the green human resource to explain 
the essentiality of citizenship behaviour and social perspective at the organisation level. The findings from the study suggest that the influence of GHRM shows a complementary partial mediation effect of AC where GHRM is distributed accordingly with AMO theory.

The study concluded the positive relation of all the proposed hypothesis of the green human resource attributes in the education sector. Prioritisation of the competence building among the employees can improve the sustainable organisation image. The education sector composes all the future generations who must be clear about the global change and solution to make to global protection in every field. The output from the study can truly affect this aspect. The feasible use of this research is to focus on and reinforce the major human management system of the education sector. This study included the valley, which is one of the centralised developed areas of the developing country. Moreover, the concerned authority should implement green human resource attributes with a better action plan and should decentralise the system to obtain equity in the human resource management system. Thus, the top-level staff should upgrade through training programs regarding green training, employee involvement in every green activity of the organisation. This will help employees to comprehend and to enhance their awareness regarding the importance of environmental management. The findings of the study shed light on the relation of $\mathrm{AC}$ and $\mathrm{OCB}$ regarding the green human resource practice in educational institutions.

\section{LIMITATIONS AND FUTURE RESEARCH}

There are some limitations in the present study, but the limitation might be fruitful for further researchers. The data collection included the secondary-level school of the developed or well-facilitated area only. The target population of the study was only the academic staff of the secondary-level schools. Meanwhile, secondarylevel schools involve a large population of complex activities, and universities of the state might influence more in the GHRM and organisational output. Future researchers can conduct this study to make a comparison of green human resource practices with rural educational institutes. Most of the countryside educational sectors still lack the essential requirements for instance proper buildings, class materials, the latest technology-based school tools, the internet, etc. For them, priorities on green human resource might be far away due to unfulfilled other essentials. Future researchers also should include the non-academic staffs including technical, operational, and technical representatives to accumulate different perceptions from the represented sector of the employees. Moreover, a comparison of GHRM in educational institutes among the developing and developed countries 
might add the globalisation of this kind of study. Besides, this can direct the future researchers to include stakeholder's perceptions and attitudes towards GHRM practices.

\section{REFERENCES}

Alfes, K., Shantz, A. D., Truss, C., \& Soane, E. C. (2013). The link between perceived human resource management practices, engagement and employee behaviour: A moderated mediation model. The International Journal of Human Resource Management, 24(2), 330-351. https://doi.org/10.1080/09585192.2012.679950

Almutawa, Z., Muenjohn, N., \& Zhang, J. (2016). The effect of human resource management system on employees' commitment: The mediating role of the AMO model. The Journal of Developing Areas, 50(6), 17-29. https://doi.org/10.1353/ jda.2016.0147

Antonioli, D., Mancinelli, S., \& Mazzanti, M. (2013). Is environmental innovation embedded within high-performance organisational changes? The role of human resource management and complementarity in green business strategies. Research Policy, 42(4), 975-988. https://doi.org/10.1016/j.respol.2012.12.005

Anwar, N., Mahmood, N. H. N., Yusliza, M. Y., Ramayah, T., Faezah, J. N., \& Khalid, W. (2020). Green human resource management for organisational citizenship behaviour towards the environment and environmental performance on a university campus. Journal of Cleaner Production, 256. https://doi.org/10.1016/j. jclepro.2020.120401

Arulrajah, A. A., \& Opatha, H. (2016). Analytical and theoretical perspectives on green human resource management: A simplified underpinning. International Business Research, 9(12), 153-164. https://doi.org/10.5539/ibr.v9n12p153

Arulrajah, A. A., Opatha, H., \& Nawaratne, N. (2015). Green human resource management practices: A review. Sri Lankan Journal of Human Resource Management, 5(1), 1-16. https://doi.org/10.4038/sljhrm.v5i1.5624

Bainbridge, H. (2015). Devolving people management to the line: How different rationales for devolution influence people management effectiveness. Personnel Review, 44(6), 847-865. https://doi.org/10.1108/PR-10-2013-0193

Barclay, D., Higgins, C., \& Thompson, R. (1995). The partial least squares (PLS) approach to casual modeling: Personal computer adoption and use as an illustration. Technology Studies, Special Issue on Research Methodology, 2(2), 285-309.

Baron, R. M., \& Kenny, D. A. (1986). The moderator-mediator variable distinction in social psychological research: Conceptual, strategic, and statistical considerations. Journal of Personality and Social Psychology, 51(6), 1173-1182. https://doi. org/10.1037/0022-3514.51.6.1173

Benn, S., Teo, S. T., \& Martin, A. (2015). Employee participation and engagement in working for the environment. Personnel Review, 44(4), 492-510. https://doi. org/10.1108/PR-10-2013-0179

Blau, P. (1964). Exchange and power in social life. New York: Wiley. 
Bombiak, E., \& Marciniuk-Kluska, A. (2018). Green human resource management as a tool for the sustainable development of enterprises: Polish young company experience. Sustainability, 10(6), 1739-1761. https://doi.org/10.3390/su10061739

Bos-Nehles, A. C., Van Riemsdijk, M. J., \& Kees Looise, J. (2013). Employee perceptions of line management performance: Applying the AMO theory to explain the effectiveness of line managers' HRM implementation. Human Resource Management, 52(6), 861-877. https://doi.org/10.1002/hrm.21578

Boselie, P. (2010). High performance work practices in the health care sector: A Dutch case study. International Journal of Manpower, 31(1), 42-58. https://doi. org/10.1108/01437721011031685

Busari, A. H., Mughal, Y. H., Khan, S. N., Rasool, S., \& Kiyani, A. A. (2017). Analytical cognitive style moderation on promotion and turnover intention. Journal of Management Development, 36(3), 438-464. https://doi.org/10.1108/JMD-122015-0184

Caesens, G., Marique, G., Hanin, D., \& Stinglhamber, F. (2016). The relationship between perceived organizational support and proactive behaviour directed towards the organization. European Journal of Work and Organizational Psychology, 25(3), 398-411. https://doi.org/10.1080/1359432X.2015.1092960

Carmeli, A., \& Colakoglu, S. N. (2005). The relationship between affective commitment and organizational citizenship behaviors: The moderating role of emotional intelligence. Research on Emotion in Organizations, 1, 77-93. https://doi. org/10.1016/S1746-9791(05)01104-1

Chaudhary, R. (2020). Green human resource management and employee green behavior: An empirical analysis. Corporate Social Responsibility and Environmental Management, 27(2), 630-641. https://doi.org/10.1002/csr.1827

Davies, I. A., \& Crane, A. (2010). Corporate social responsibility in small-and mediumsize enterprises: Investigating employee engagement in fair trade companies. Business Ethics: A European Review, 19(2), 126-139. https://doi.org/10.1111/ j.1467-8608.2010.01586.x

Deshwal, D. P. (2015). Green HRM: An organizational strategy of greening people. International Journal of Applied Research, 1(13), 176-181.

DuBois, C. L., \& Dubois, D. A. (2012). Strategic HRM as social design for environmental sustainability in organization. Human Resource Management, 51(6), 799-826. https://doi.org/10.1002/hrm.21504

Dumont, J., Shen, J., \& Deng, X. (2017). Effects of green HRM practices on employee workplace green behavior: The role of psychological green climate and employee green values. Human Resource Management, 56(4), 613-627. https://doi. org/10.1002/hrm.21792

Eisenberger, R., Shoss, M. K., Karagonlar, G., Gonzalez-Morales, M. G., Wickham, R. E., \& Buffardi, L. C. (2014). The supervisor POS-LMX-subordinate POS chain: Moderation by reciprocation wariness and supervisor's organizational embodiment. Journal of Organizational Behavior, 35(5), 635-656. https://doi. org/10.1002/job.1877 
Elorza, U., Aritzeta, A., \& Ayestarán, S. (2011). Exploring the black box in Spanish firms: The effect of the actual and perceived system on employees' commitment and organizational performance. The International Journal of Human Resource Management, 22(07), 1401-1422. https://doi.org/10.1080/09585192.2011.561956

Fitzgerald, G. (2011). The role of greening businesses as drivers of employees' behavioural change towards sustainable waste and resource management practices across all spheres of life. The 1st World Sustainability Forum, 735. https://doi.org/10.3390/ wsf-00735

Fornell, C., \& Larcker, D. F. (1981). Structural equation models with unobservable variables and measurement error: Algebra and statistics. Journal of Marketing Research, 18(3),382-388. https://doi.org/10.2307/3150980

García, J. A. M., \& Tomas, J. M. (2016). Deconstructing AMO framework: A systematic review. Intangible Capital, 12(4), 1040-1087. https://doi.org/10.3926/ic.838

Gardner, T. M., Wright, P. M., \& Moynihan, L. M. (2011). The impact of motivation, empowerment, and skill-enhancing practices on aggregate voluntary turnover: The mediating effect of collective affective commitment. Personnel Psychology, 64(2), 315-350. https://doi.org/10.1111/j.1744-6570.2011.01212.x

Grego-Planer, D. (2019). The relationship between organizational commitment and organizational citizenship behaviors in the public and private sectors. Sustainability, 11(22), 6395. https://doi.org/10.3390/su11226395

Gupta, H. (2018). Assessing organizations performance on the basis of GHRM practices using BWM and Fuzzy TOPSIS. Journal of Environmental Management, 226, 201-216. https://doi.org/10.1016/j.jenvman.2018.08.005

Haddock-Millar, J., Sanyal, C., \& Müller-Camen, M. (2016). Green human resource management: A comparative qualitative case study of a United States multinational corporation. The International Journal of Human Resource Management, 27(2), 192-211. https://doi.org/10.1080/09585192.2015.1052087

Hair, J. F., Sarstedt, M., Ringle, C. M., \& Mena, J. A. (2012). An assessment of the use of partial least squares structural equation modeling in marketing research. Journal of the Academy of Marketing Science, 40(3), 414-433. https://doi.org/10.1007/ s11747-011-0261-6

Harvey, G., Williams, K., \& Probert, J. (2013). Greening the airline pilot: HRM and the green performance of airlines in the UK. The International Journal of Human Resource Management, 24(1), 152-166. https://doi.org/10.1080/09585192.2012 .669783

Henseler, J., Hubona, G., \& Ray, P. A. (2016). Using PLS path modeling in new technology research: Updated guidelines. Industrial Management \& Data Systems, 116(1), 2-20. https://doi.org/10.1108/IMDS-09-2015-0382

Henseler, J., Ringle, C. M., \& Sarstedt, M. (2015). A new criterion for assessing discriminant validity in variance-based structural equation modeling. Journal of the Academy of Marketing Science, 43(1), 115-135. https://doi.org/10.1007/s11747-014-0403-8

Jackson, S. E., Renwick, D. W., Jabbour, C. J., \& Muller-Camen, M. (2011). State-ofthe-art and future directions for green human resource management: Introduction to the special issue. German Journal of Human Resource Management, 25(2), 99-116. https://doi.org/10.1177/239700221102500203 
Jafri, S. (2012). Green HR practices: An empirical study of certain automobile organizations of India. Human Resource Management, 42, 6193-6198.

Juma, N., \& Lee, J.-Y. (2012). The moderating effects of traditionality-modernity on the effects of internal labor market beliefs on employee affective commitment and their turnover intention. The International Journal of Human Resource Management, 23(11), 2315-2332. https://doi.org/10.1080/09585192.2011.616522

Kaur, H. (2013). Today's success mantra: Going green at functional areas of HRM. International Journal of Management \& Business Studies, 3(1), 96-99.

Kim, Y. J., Kim, W. G., Choi, H.-M., \& Phetvaroon, K. (2019). The effect of green human resource management on hotel employees' eco-friendly behavior and environmental performance. International Journal of Hospitality Management, 76, 83-93. https://doi.org/10.1016/j.ijhm.2018.04.007

Knies, E., \& Leisink, P. (2014). Linking people management and extra-role behaviour: Results of a longitudinal study. Human Resource Management Journal, 24(1), 57-76. https://doi.org/10.1111/1748-8583.12023

Lin, C. C., \& Peng, T. K. (2010). From organizational citizenship behaviour to team performance: The mediation of group cohesion and collective efficacy. Management and Organization Review, 6(1), 55-75. https://doi.org/10.1111/ j.1740-8784.2009.00172.x

Liu, X., \& Deng, J. (2011). Development of organizational commitment based on the social exchange theory. Paper presented at the 2011 International Conference on Management and Service Science, 12-14 August 2011, Wuhan, China. https:// doi.org/10.1109/ICMSS.2011.5997998

Luu, T. T. (2019). Green human resource practices and organizational citizenship behavior for the environment: The roles of collective green crafting and environmentally specific servant leadership. Journal of Sustainable Tourism, 27(8), 1167-1196. https://doi.org/10.1080/09669582.2019.1601731

Memon, A. H., \& Rahman, I. A. (2014). SEM-PLS analysis of inhibiting factors of cost performance for large construction projects in Malaysia: Perspective of clients and consultants. The Scientific World Journal, 2014. Article ID: 165158. https:// doi.org/10.1155/2014/165158

Mercurio, Z. A. (2015). Affective commitment as a core essence of organizational commitment: An integrative literature review. Human Resource Development Review, 14(4), 389-414. https://doi.org/10.1177/1534484315603612

Meyer, J. P., Allen, N. J., \& Smith, C. A. (1993). Commitment to organizations and occupations: Extension and test of a three-component conceptualization. Journal of Applied Psychology, 78(4), 538-551. https://doi.org/10.1037/00219010.78.4.538

Meyer, J. P., Paunonen, S. V., Gellatly, I. R., Goffin, R. D., \& Jackson, D. N. (1989). Organizational commitment and job performance: It's the nature of the commitment that counts. Journal of Applied Psychology, 74(1), 152-156. https:// doi.org/10.1037/0021-9010.74.1.152 
Meyer, J. P., Stanley, D. J., Herscovitch, L., \& Topolnytsky, L. (2002). Affective, continuance, and normative commitment to the organization: A meta-analysis of antecedents, correlates, and consequences. Journal of Vocational Behavior, 61(1), 20-52. https://doi.org/10.1006/jvbe.2001.1842

Moktadir, A., Rahman, T., Jabbour, C. J. C., Ali, S. M., \& Kabir, G. (2018). Prioritization of drivers of corporate social responsibility in the footwear industry in an emerging economy: A fuzzy AHP approach. Journal of Cleaner Production, 201, 369-381. https://doi.org/10.1016/j.jclepro.2018.07.326

Muehling, D. D. (1987). An investigation of factors underlying attitude-toward-advertisingin-general. Journal of Advertising, 16(1), 32-40. https://doi.org/10.1080/0091336 7.1987.10673058

Nejati, M., Rabiei, S., \& Jabbour, C. J. C. (2017). Envisioning the invisible: Understanding the synergy between green human resource management and green supply chain management in manufacturing firms in Iran in light of the moderating effect of employees' resistance to change. Journal of Cleaner Production, 168, 163-172. https://doi.org/10.1016/j.jclepro.2017.08.213

Neves, P. C., Paixão, R., Alarcão, M., \& Gomes, A. D. (2014). Organizational citizenship behavior in schools: Validation of a questionnaire. The Spanish Journal of Psychology, 17, 1-24. https://doi.org/10.1017/sjp.2014.20

Norris-Watts, C., \& Levy, P. E. (2004). The mediating role of affective commitment in the relation of the feedback environment to work outcomes. Journal of Vocational Behavior, 65(3), 351-365. https://doi.org/10.1016/j.jvb.2003.08.003

Norton, T. A., Parker, S. L., Zacher, H., \& Ashkanasy, N. M. (2015). Employee green behavior: A theoretical framework, multilevel review, and future research agenda. Organization \& Environment, 28(1), 103-125. https://doi. org/10.1177/1086026615575773

Norton, T. A., Zacher, H., \& Ashkanasy, N. M. (2014). Organisational sustainability policies and employee green behaviour: The mediating role of work climate perceptions. Journal of Environmental Psychology, 38, 49-54. https://doi. org/10.1016/j.jenvp.2013.12.008

Opatha, H. (2013). Green human resource management: A simplified introduction. Proceedings of the 1st HR Dialogue of Faculty of Management Studies and Commerce, University of Sri Jayewardenepura, Nugegoda.

Organ, D. W. (1990). The motivational basis of organizational citizenship behavior. Research in Organizational Behavior, 12(1), 43-72.

Owino, W., \& Kwasira, J. (2016). Influence of selected green human resource management practices on environmental sustainability at Menengai Oil Refinery Limited Nakuru, Kenya. Journal of Human Resource Management, 4(3), 19-27. https:// doi.org/10.11648/j.jhrm.20160403.11

Paillé, P., Chen, Y., Boiral, O., \& Jin, J. (2014). The impact of human resource management on environmental performance: An employee-level study. Journal of Business Ethics, 121(3), 451-466. https://doi.org/10.1007/s10551-013-1732-0

Pasban, M., \& Nojedeh, S. H. (2016). A review of the role of human capital in the organization. Procedia-Social and Behavioral Sciences, 230, 249-253. https:// doi.org/10.1016/j.sbspro.2016.09.032 
Pham, N. T., Phan, Q. P. T., Tučková, Z., Vo, N., \& Nguyen, L. H. (2018). Enhancing the organizational citizenship behavior for the environment: The roles of green training and organizational culture. Management \& Marketing. Challenges for the Knowledge Society, 13(4), 1174-1189. https://doi.org/10.2478/mmcks-2018-0030

Pinzone, M., Guerci, M., Lettieri, E., \& Redman, T. (2016). Progressing in the change journey towards sustainability in healthcare: The role of 'Green' HRM. Journal of Cleaner Production, 122, 201-211. https://doi.org/10.1016/j.jclepro.2016.02.031

Podsakoff, P. M., \& Organ, D. W. (1986). Self-reports in organizational research: Problems and prospects. Journal of Management, 12(4), 531-544. https://doi. org/10.1177/014920638601200408

Quansah, N. (2013). The impact of HRM practices on organisational performance: The case study of some selected rural banks. Doctoral dissertation, Kwame Nkrumah University of Science and Technology.

Rajiani, I., Musa, H., \& Hardjono, B. (2016). Research article ability, motivation and opportunity as determinants of green human resources management innovation, Research Journal of Business Management, 10(1-3), 51-57. https://doi. org/10.3923/rjbm.2016.51.57

Renwick, D. W., Redman, T., \& Maguire, S. (2013). Green human resource management: A review and research agenda. International Journal of Management Reviews, 15(1), 1-14. https://doi.org/10.1111/j.1468-2370.2011.00328.x

Revilla, M. A., Saris, W. E., \& Krosnick, J. A. (2014). Choosing the number of categories in agree-disagree scales. Sociological Methods \& Research, 43(1), 73-97. https:// doi.org/10.1177/0049124113509605

Shaaban, S. (2018). The impact of motivation on organisational citizenship behaviour (OCB): The mediation effect of employees' engagement. Journal of Human Resource Management, 6(2), 58-66. https://doi.org/10.11648/j.jhrm.20180602.13

Shanmugapriya, S., \& Subramanian, K. (2016). Developing a PLS path model to investigate the factors influencing safety performance improvement in construction organizations. KSCE Journal of Civil Engineering, 20(4), 1138-1150. https://doi. org/10.1007/s12205-015-0442-9

Shantha, K. V. A. (2019). Individual investors' learning behavior and its impact on their herd bias: An integrated analysis in the context of stock trading. Sustainability, 11(5), 1448-1472. https://doi.org/10.3390/su11051448

Shen, J., Dumont, J., \& Deng, X. (2016). Employees' perceptions of green HRM and non-green employee work outcomes: The social identity and stakeholder perspectives. Group \& Organization Management, 43(4), 594-622, https://doi. org/10.1177/1059601116664610

Shore, L. M., \& Wayne, S. J. (1993). Commitment and employee behavior: Comparison of affective commitment and continuance commitment with perceived organizational support. Journal of Applied Psychology, 78(5), 774-780. https:// doi.org/10.1037/0021-9010.78.5.774

Siyambalapitiya, J., Zhang, X., \& Liu, X. (2018). Green human resource management: A proposed model in the context of Sri Lanka's tourism industry. Journal of Cleaner Production, 201, 542-555. https://doi.org/10.1016/j.jclepro.2018.07.305 
Sobhani, F. A., Amran, A., \& Zainuddin, Y. (2009). Revisiting the practices of corporate social and environmental disclosure in Bangladesh. Corporate Social Responsibility and Environmental Management, 16(3), 167-183. https://doi. org/10.1002/csr.193

Srivastava, A. P., \& Shree, S. (2019). Examining the effect of employee green involvement on perception of corporate social responsibility. Management of Environmental Quality: An International Journal, 30(1), 197-210. https://doi.org/10.1108/ MEQ-03-2018-0057

Stinglhamber, F., Marique, G., Caesens, G., Hanin, D., \& De Zanet, F. (2015). The influence of transformational leadership on followers' affective commitment: The role of perceived organizational support and supervisor's organizational embodiment. Career Development International, 20(6), 583-603. https://doi.org/10.1108/CDI12-2014-0158

Tang, G., Chen, Y., Jiang, Y., Paille, P., \& Jia, J. (2018). Green human resource management practices: Scale development and validity. Asia Pacific Journal of Human Resources, 56(1), 31-55. https://doi.org/10.1111/1744-7941.12147

Tariq, S., Jan, F. A., \& Ahmad, M. S. (2016). Green employee empowerment: A systematic literature review on state-of-art in green human resource management. Quality \& Quantity, 50(1), 237-269. https://doi.org/10.1007/s11135-014-0146-0

Tenenhaus, M., Vinzi, V. E., Chatelin, Y.-M., \& Lauro, C. (2005). PLS path modeling. Computational Statistics \& Data Analysis, 48(1), 159-205. https://doi. org/10.1016/j.csda.2004.03.005

Wolf, E., Harrington, K., Clark, S., \& Miller, M. (2013). Sample size requirements for structural equation models: An evaluation of power, bias, and solution propriety. Educational and Psychological Measurement, 73, 913-934. https://doi. org/10.1177/0013164413495237

Yusliza, M.-Y., Othman, N. Z., \& Jabbour, C. J. C. (2017). Deciphering the implementation of green human resource management in an emerging economy. Journal of Management Development, 36(10), 1230-1246. https://doi.org/10.1108/JMD-012017-0027

Zientara, P., \& Zamojska, A. (2018). Green organizational climates and employee proenvironmental behaviour in the hotel industry. Journal of Sustainable Tourism, 26(7), 1142-1159. https://doi.org/10.1080/09669582.2016.1206554

Zibarras, L. D., \& Coan, P. (2015). HRM practices used to promote pro-environmental behavior: A UK survey. The International Journal of Human Resource Management, 26(16), 2121-2142. https://doi.org/10.1080/09585192.2014.9724 29 


\section{APPENDIX}

\begin{tabular}{|c|c|c|c|}
\hline Variables & Code & Indicators & Reference \\
\hline \multirow[t]{4}{*}{ Ability } & GCB1 & Attract green job candidates & (Tang et al., 2018) \\
\hline & GCB2 & $\begin{array}{l}\text { Recruits employees who have green } \\
\text { awareness }\end{array}$ & $\begin{array}{l}\text { (Gupta, 2018; Tang } \\
\text { et al., 2018) }\end{array}$ \\
\hline & GCB3 & $\begin{array}{l}\text { Attention to the environmental } \\
\text { management practices }\end{array}$ & $\begin{array}{l}\text { (Renwick et al., } \\
\text { 2013) }\end{array}$ \\
\hline & GCB4 & Raising the level of eco-literacy & $\begin{array}{l}\text { (Renwick et al., } \\
\text { 2013) }\end{array}$ \\
\hline \multirow[t]{4}{*}{ Motivation } & GPM1 & $\begin{array}{l}\text { Green performance indicators included } \\
\text { in performance management system and } \\
\text { appraisals }\end{array}$ & $\begin{array}{l}\text { (Gupta, 2018; Tang } \\
\text { et al., 2018) }\end{array}$ \\
\hline & GPM2 & $\begin{array}{l}\text { Employee appraisals, emphasise } \\
\text { environmental skills and competencies }\end{array}$ & (Pinzone et al., 2016) \\
\hline & GPM3 & $\begin{array}{l}\text { Performance appraisals include } \\
\text { environmental objectives }\end{array}$ & (Pinzone et al., 2016) \\
\hline & GPM4 & $\begin{array}{l}\text { Financial/tax incentives (bicycle } \\
\text { loans, use of less polluting cars) }\end{array}$ & $\begin{array}{l}\text { (Gupta, 2018; Tang } \\
\text { et al., 2018) }\end{array}$ \\
\hline \multirow[t]{3}{*}{ Opportunity } & GEI1 & $\begin{array}{l}\text { Increasing employees' psychological } \\
\text { empowerment, enhances their } \\
\text { willingness to make suggestions } \\
\text { for EM improvements }\end{array}$ & $\begin{array}{l}\text { (Bos-Nehles et al., } \\
\text { 2013) }\end{array}$ \\
\hline & GEI2 & $\begin{array}{l}\text { Formal or informal communication } \\
\text { channels to spread green culture }\end{array}$ & $\begin{array}{l}\text { (Almutawa et al., } \\
\text { 2016; Bos-Nehles et } \\
\text { al., 2013) }\end{array}$ \\
\hline & GEI3 & $\begin{array}{l}\text { Encouraging employees to make } \\
\text { suggestions for EM improvements }\end{array}$ & $\begin{array}{l}\text { (Bos-Nehles et al., } \\
\text { 2013) }\end{array}$ \\
\hline \multirow[t]{3}{*}{$\begin{array}{l}\text { Organisation } \\
\text { change } \\
\text { behaviour }\end{array}$} & OCB1 & $\begin{array}{l}\text { Employees actively participate in } \\
\text { environmental events organised in and/or } \\
\text { by the trust }\end{array}$ & $\begin{array}{l}\text { (Neves et al., 2014; } \\
\text { Paillé et al., 2014) }\end{array}$ \\
\hline & OCB2 & $\begin{array}{l}\text { Employees stay informed on environmental } \\
\text { activities in the trust }\end{array}$ & $\begin{array}{l}\text { (Neves et al., } \\
\text { 2014), (Rajiani et al., } \\
\text { 2016) }\end{array}$ \\
\hline & OCB3 & $\begin{array}{l}\text { Employees undertake environmental } \\
\text { actions that contribute positively to the } \\
\text { image of the trust }\end{array}$ & $\begin{array}{l}\text { (Neves et al., 2014; } \\
\text { Rajiani et al., 2016) }\end{array}$ \\
\hline
\end{tabular}




\begin{tabular}{llll}
\hline Variables & Code & Indicators & Reference \\
\hline $\begin{array}{l}\text { Affective } \\
\text { commitment }\end{array}$ & AC1 & $\begin{array}{l}\text { Employees believe in the value of } \\
\text { environmental management for the trust }\end{array}$ & (Neves et al., 2014) \\
& AC2 & $\begin{array}{l}\text { Employees think environmental } \\
\text { management is a good strategy for the trust }\end{array}$ & $\begin{array}{l}\text { (Neves et al., 2014; } \\
\text { Shaaban, 2018) } \\
\text { AC3 }\end{array}$ \\
& $\begin{array}{l}\text { Employees think management is making } \\
\text { a mistake by investing in reducing the } \\
\text { environmental impact of the trust }\end{array}$ & $\begin{array}{l}\text { Pinzone et al., 2016) } \\
\text { Employees believe environmental } \\
\text { management serves an important purpose } \\
\text { in the trust }\end{array}$ & (Kim et al., 2019; \\
& Pinzone et al., 2016) & \\
\hline
\end{tabular}

